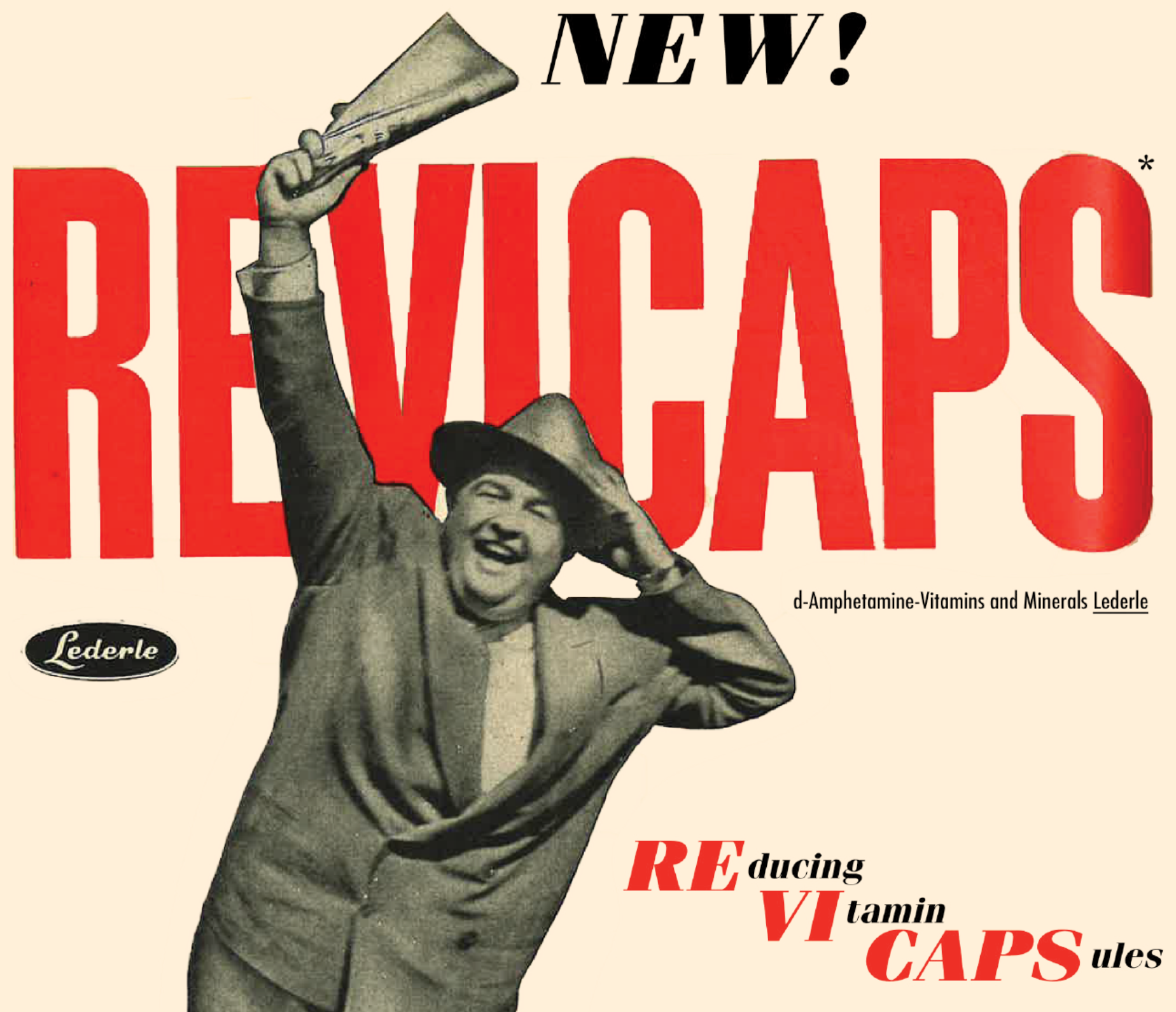

From the point of view of the medical profession, there is nothing funny about the fat man or the overweight housewife. At age 55, 20 per cent overweight means 20 per cent higher mortality. And among those who are 40 per cent overweight, mortality is 64 per cent higher?

$\rightarrow$ REVICAPS (REducing VItamin CAPSules) is the new scientifically formulated product to help reduce obesity.

REVICAPS reduce appetite.

REVICAPS provide all essential vitamins and minerals. REVICAPS are being heavility promoted by sampling, direct mail, and journal advertising.

Keep up your supplies of this profitable, new, prescription product for daily use. 


\section{THE EDITOR COMMENTS}

\section{WHAT MAKES AN OCCUPATION A PROFESSION?}

What makes one occupation a trade and another a profession? It is not entirely the labor performed or the people who perform it. For one man can dig a ditch with such love and care that he is not so much digging the ditch, as draining the land that crops and life may thrive where once was nothing but waste. Another man can operate his "profession" along such monetary lines that he becomes merely a purveyor of commodities.

Just what is a profession? The famous and most widely accepted definition of a profession is the one handed down by the late Justice Brandeis of the United States Supreme Court: "A profession is an occupation requiring extensive preliminary intellectual training pursued primarily for others, and not merely for oneself and accepting as a measure of achievement one's contributions to society rather than financial advancement."

What makes an occupation a profession? The ethical attitude within the mind and heart of each person who lives by that occupation. But it is not enough to have that attitude in your mind and heart. It must be brought forth and cultivated, that the rest of the world may know of its existence.
At a large gathering of pharmacists which we attended recently, the most frequently spoken word was "Merchandise" and it was spoken as a command. The latest advertisement run in the public press by one of the provincial pharmacy groups carried the phrase "The only merchant on Main Street who must have a diploma."

This tremendous accent on merchandising, if not tempered by an even greater accent on professionalism, can lead but to one end. Pharmacy stands to lose stature in the eyes of the public.

Of course the pharmacist must merchandise, and the nature of his business demands that he be a merchant. But he is, or should be, a pharmacist first. It is to be a pharmacist, that he has spent many years in learning his craft. If his only desire is to be a merchant, he could have opened a shop four years earlier.

It is not enough for craftsmen to think of their life work as a profession; they must prove by every word they speak and every action they perform that it is a profession. Evolution through the years will then, and only then, make it so.
Rxfor plus sale Get FREE Goods when you order
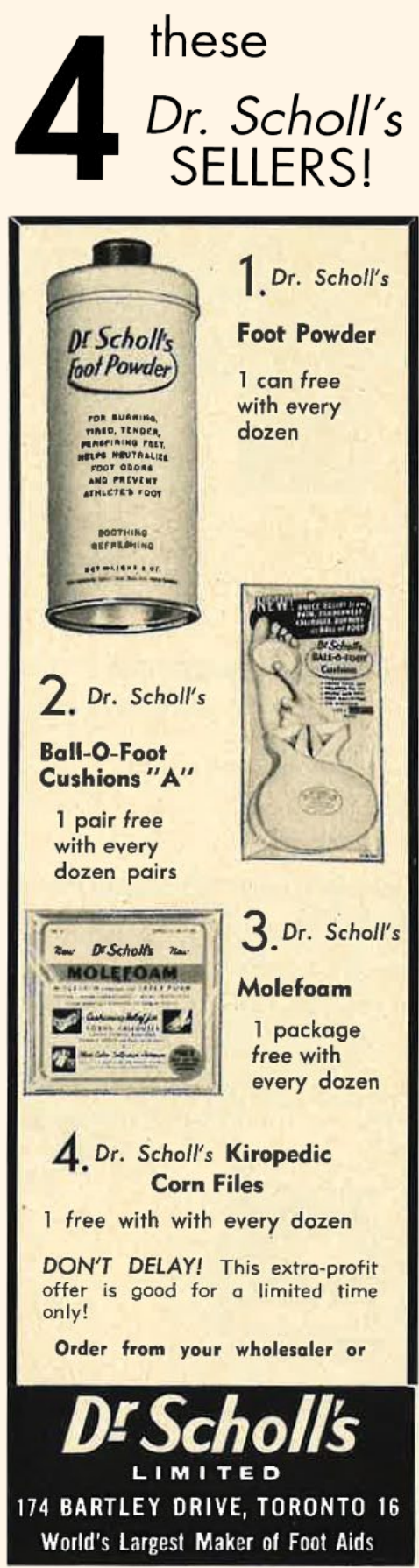